INTERNATIONAL HIGHER EDUCATION Number 71 Spring 2013

Pages 6-8

\title{
Imagining the University \\ RONALD BARNETT
}

Ronald Barnett is emeritus professor of higher education, at the Institute of Education, University of London. His latest book is Imagining the University (Routledge, 2013). E-mail: R.Barnett@ioe.ac.uk.

The pages of International Higher Education are witness to continuous changes in universities across the world. These capacities easily identify with changes and hold conversations about them even across quite different settings—so that a worldwide conversation is taking place here.

These reflections open up some major issues. That conversations can be conducted cross-nationally is indicative of the changes underway being global in nature. These changes have been identified over the past 30 years, including attached terms such as the emergence of a global knowledge economy and marketization and neoliberalism. More recently, terms such as cognitive capitalism and knowledge capitalism have been offered. Connected, too, are developments in computing technologies that are making possible public, interactive, and multimodal engagements with knowledge.

Partly as a result of such global forces, one witnesses the rise of the entrepreneurial university. This university has come to understand to be in command of services and products-intimately connected with the formation 
and transmission of knowledge-that have exchanged value in the market. From being a small institution on the fringe of society, the university has become a major institution centrally involved in the formation of a cognitively based world.

\section{RESPONSES}

There have been several reactions to these phenomena. First, responders are those who write up the very idea of the entrepreneurial university. They are a composite of those in the political sphere; the senior levels of the management and leadership of universities; state agencies; independent consultants; and think tanks. Second, the academic critics espouse a language, in a critical vein, of neoliberalism, performativity, academic capitalism, and commodification. Third, a group of critics critique the university for being laggardly in taking on the challenges of the age. Such critics point to the opportunities for the emergence of the edgeless university, the borderless university, and the collaborative university. In this conception, the university is always behind the game, and rather slow to embrace opportunities.

Last, there are the philosophers and social theorists: in expounding their views of the university, they tend to operate at a rather abstract level. In critiquing the university, they desist from offering specific proposals but rather focus on the communicative conditions that need to be satisfied by any university worthy of the name. Such an institution could be exemplified in a university of dissensus, or an ideal speech situation, or (even more vaguely) a university without condition. 


\section{FORMS OF IMAGINATION}

It would be tempting to characterize this whole debate as one lacking in imagination, but that would be unfair. On the contrary, as is evident in our observations, there are several forms of imagining of the university, and these forms of imagination are amplified in the (sometimes obscure) academic literature.

Forms of the imagination fall along certain fault lines. Those in favor of the entrepreneurial university are full of breezy optimism, while those evincing the standard academic critiques are characterized by a dismal pessimism (to the effect that the world of higher education apparently can be no other than its current state). Some imaginations work on the surface level (speaking uncritically of quality, excellence, and technology), while others attempt to dig down to the deep underlying global structures affecting the university. Also, as stated, some forms of imagination implicitly endorse the way matters are running for the university, while others seek to critique it.

\section{Poverty OF IMAgination}

It turns out, then, that far from being a dearth of the imagination, over recent years, there has been a veritable flow, if not tsunami of ideas. There are, though, two critical points to be made.

First, as implied, few ideas of the university are emerging out of the academic literature into the public debate. Thus, one reason is that the majority of those ideas do not fit with the mood of our time. That mood is one of value for money from public services, the customer pays, and the belief that a test of the value of an enterprise is the presence of purchasers for it. There has emerged, 
therefore, a discursive regime in which the idea of the entrepreneurial university sits very nicely. It is hardly surprising if it seems to be the only game in the university town.

But another reason is helping to explain the dearth of ideas in the public domain: perhaps those ideas in the academic literature do not deserve to enjoy wide circulation. After all, an imaginative idea of the university is not necessarily a good idea. Perhaps more than an increase in the ideas of the university, therefore, better ideas are needed.

Second, despite the fecundity of ideas, one can still speak of a poverty of the imagination in this sense. By and large, ideas are required of the university that are at once critical in tone, positive in spirit, and with an awareness of the deep and global structures that undergird universities. Much of the academic literature is, as stated, unduly pessimistic: can we therefore be at once realistic about the situation in which the university finds itself worldwide and yet be optimistic, coming forth with imaginative ideas about the university that just might be brought off, even if the cards are stacked against the university? What are needed, surely, are not merely utopias of the university but feasible utopias.

\section{A Feasible Utopia?}

Here is a contender for being one such feasible utopia, namely that of the ecological university. The ecological university would be seized of its being intertwined-at very deep levels of its being-with the global knowledge economy and with forces for marketization and competition. But it would look for spaces in which it could live out the values and ideas deeply embedded in the university—of truthfulness, inquiry, critical dialogue, rational dispute, and even 
iconoclastic endeavor. The ecological university would also be sensitive to its engaging with different ecologies, such as those of knowledge, culture, institutions, and the economy; and it would be sensitive to these ecologies working at all levels from that of the individual person through communities and societies to the world itself. Further, while the idea of ecology is characteristically associated with that of sustainability, the ecological university would not be satisfied with that idea (with merely sustaining students, or society, or even the world) but would look to promote well-being at every level.

\section{CONCLUSION}

The main point of this article is to urge for more imagination in thinking about the university; imagination that even offers feasible utopias. The suggestion here of an ecological university is but one offering in that vein. However, a university that wanted to see itself as an ecological university would become an imagining university. For the task of becoming an ecological university requires collective imagining. The art of university leadership, accordingly, becomes here in part one of encouraging and orchestrating collective imagining, so that a university realizes its possibilities at every level and in all of its activities. This, in turn, calls for nothing less than that a new kind of spaciousness should open in our universities, a spaciousness of air, no less. 